\title{
READING BETWEEN THE LOINS: A CURIOUS ANOMALY IN THE PORTRAYAL OF THE MALE PHYSIQUE IN GREEK SCULPTURE
}

\author{
P Tennant (University of KwaZulu-Natal, Pietermaritzburg)
}

Despite their apparent mastery of the representation of anatomical detail, Greek and Greco-Roman sculptors from the Classical period onwards regularly exaggerated the prominence of the "iliac crest" and its extension into the lower abdomen, creating the so-called cuirasse esthétique. This article explores possible reasons for this phenomenon.

A cursory glance at three examples of ancient Greek sculpture - spanning the early and late Archaic periods and the early Classical era - creates the overriding impression of a progression towards anatomical realism.

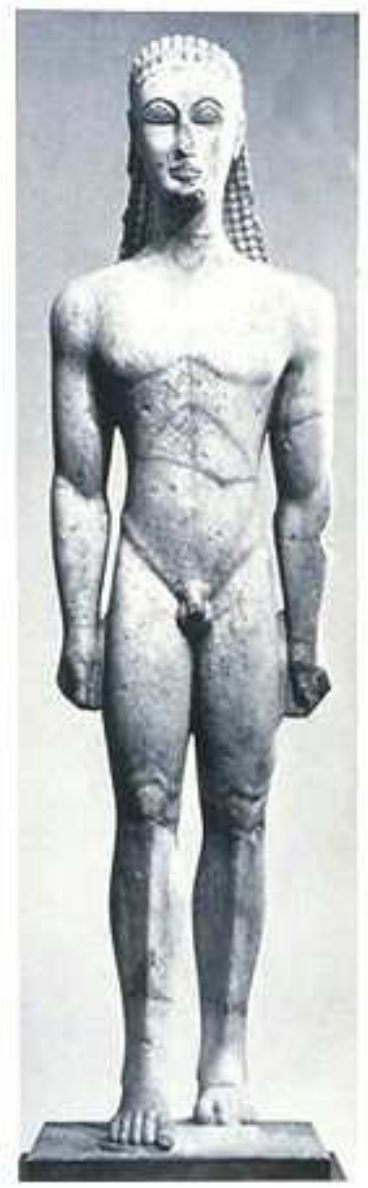

Fig.1: New York kouros

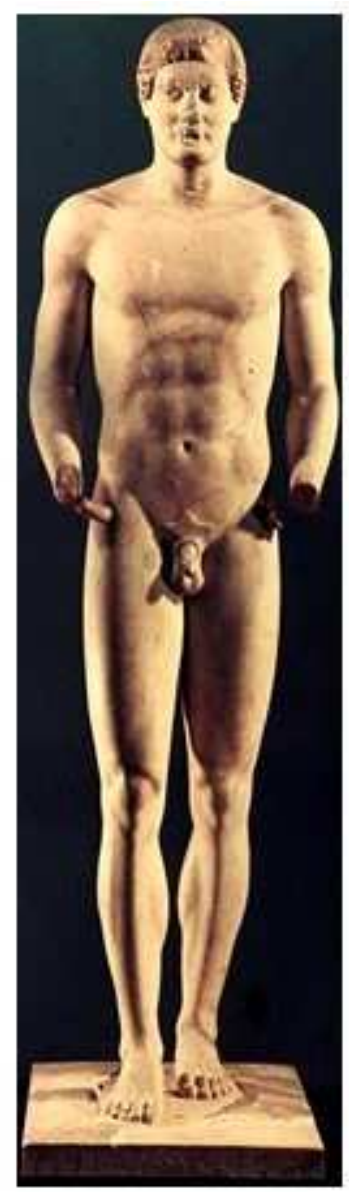

Fig. 2: Aristodikos

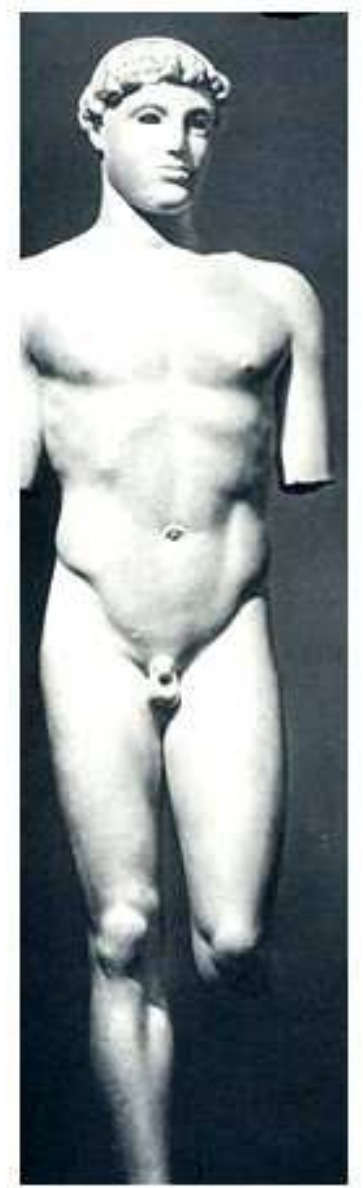

Fig. 3:Kritios Boy

In the case of the so-called "New York" kouros (late $7^{\text {th }}$ century BC), it is clear that anatomical realism is subordinate to balance and symmetry - the inevitable product 
of the grid-scheme ${ }^{1}$ employed in determining the relationship of the various parts of the body. Salient features are the segmented effect created by grooves and ridges most obvious in the groin area - and the schematic patterning achieved through these surface details. Very different is the next kouros, which represents a man called Aristodikos (Fig. 2) and which dates from the last quarter of the $6^{\text {th }}$ century BC. Here we have a good example of the degree of anatomical accuracy achieved by sculptors of the late Archaic period. However, despite these advances, the figure still displays the typically rigid, symmetrical and predominantly frontal pose of the Archaic kouros.

The beginning of the Classical period of Greek sculpture marked a decisive break away from the limitations of the Archaic mode. The well-known Kritios Boy (Fig. 3) is regularly used to illustrate how the Greek kouros eventually "came to life". The most notable feature, of course, is how the sculptor has accurately shown that the mass of the body is concentrated on the figure's left leg and that this imbalance is reflected in the tilt of the pelvis and a consequent subtle " $\mathrm{S}$ " curve of the vertical axis, accentuated by the slight turn and downward tilt of the head.

While this very cursory survey serves to illustrate the progression towards greater naturalism and anatomical accuracy in the portrayal of the male physique, there is a curious anomaly that becomes particularly evident in the high Classical period and which remains a salient characteristic of the portrayal of the male physique right throughout the GrecoRoman period and beyond. I refer to the very prominent iliac crest and to the shape, protuberance and exaggerated ridge of the lower abdomen, well illustrated by Polykleitos' Doryphoros, or 'Spearbearer" (Fig. 4), created in the middle of the $5^{\text {th }}$ century BC.

The art historian Kenneth Clark (1956:35) comments on the manner in which Polykleitos accentuated the system of rendering the male torso, as exemplified by the Kritios Boy and other earlier works: 'Polycletus' control of muscle-architecture was evidently far more rigorous, and from that derives that standard schematisation of the torso known in French as the cuirasse esthétique (Fig. 5), a disposition of

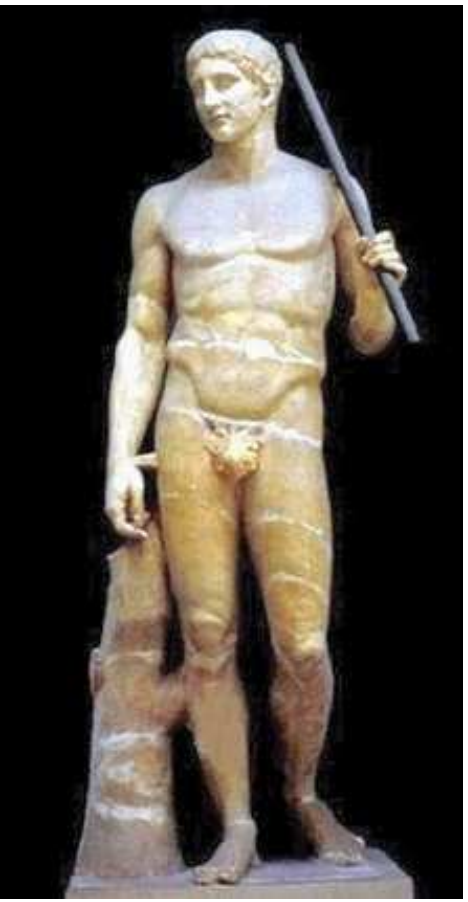

Fig. 4: Doryphoros muscles so formalized that it was in fact used in the design of armour". Clark (1956:35) goes on to remark that "[t]he cuirasse esthétique, which so greatly delighted the artists of the Renaissance, is one of the features of antique art which has done most to alienate modern taste". Polykleitos' original statue was made of bronze,

This scheme was based on the second Egyptian canon: if the distance between the eyes and the toes is divided into twenty-one equal squares, the knees occupy the seventh square and the navel the thirteenth. 
and, as is often the case, we have to rely on marble copies. Not so in the case of the celebrated Riace Warriors (Figs. 6, 7), discovered off the coast of Italy in 1972.

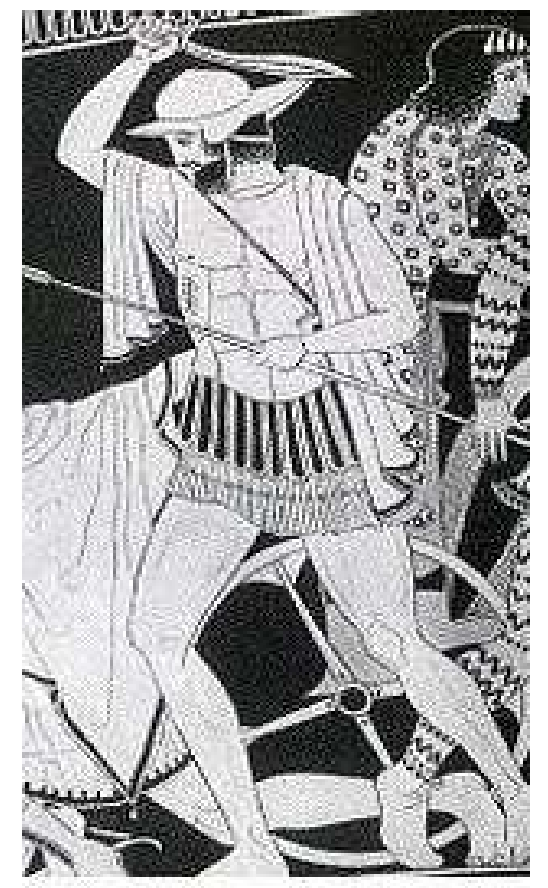

Fig. 5: Detail from

Amazonomachy, c.450 BC

(Niobid Painter)

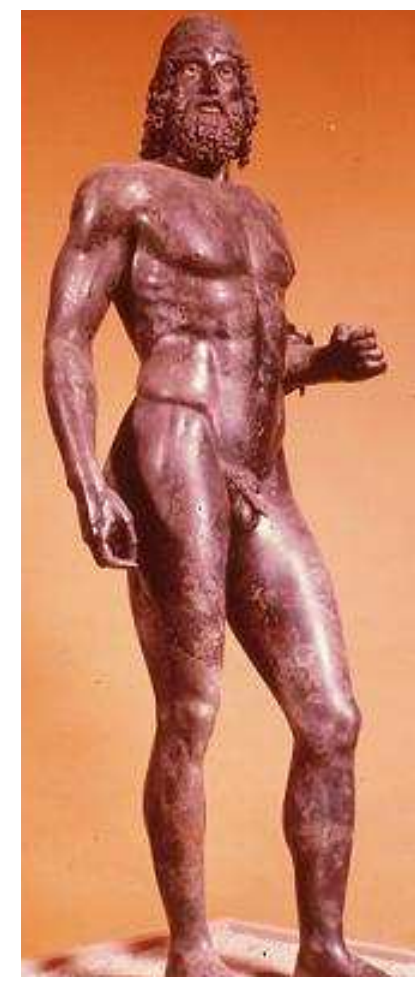

Fig. 6:

Riace Warrior

A

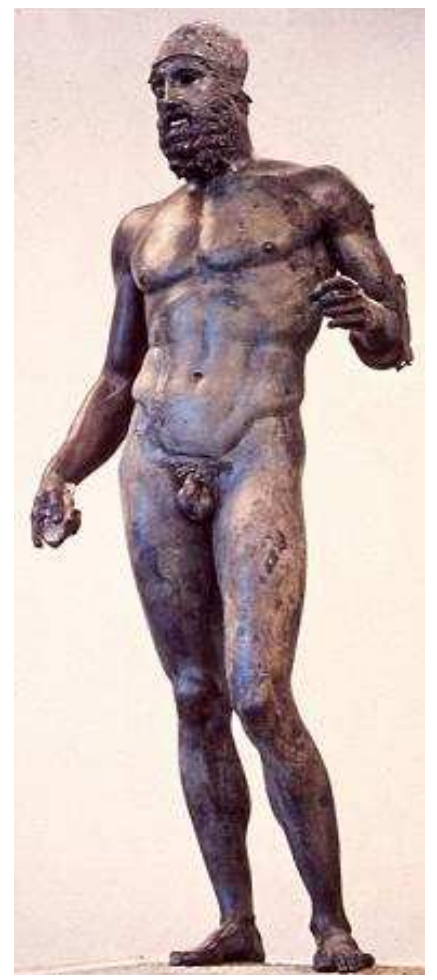

Fig. 7:

Riace Warrior

$B$

As in the case of the Doryphoros, one's attention is drawn to the very distinctive overhang of the iliac crest and the continuation of this ridge in a smooth and sinuous contour marking off the groin area from the upper thighs. While modern athletes and particularly body-builders - do develop quite prominent iliac crests (in addition to the proverbial "six-pack" abdominal muscles), the whole configuration of the lower abdomen of the Doryphoros and the Riace Warriors is markedly different from what one observes in reality. This point can be illustrated by studying an example of a modern body-builder, whose muscle development, typically, is taken to extremes.

Note, in particular, how the lower abdomen of this athlete (Fig. 8) is characterized by sinewy ridges that extend in almost straight lines towards the groin and which protrude beyond the surface of the enclosed abdominal area - somewhat reminiscent of the "New York" kouros above - and not by a smoothly moulded and protuberant cuirass or carapace, whose lower portion has an almost semicircular contour and uniform protrusion.

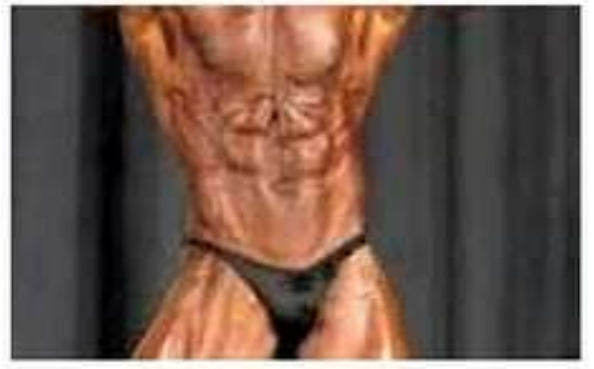

Fig. 8 


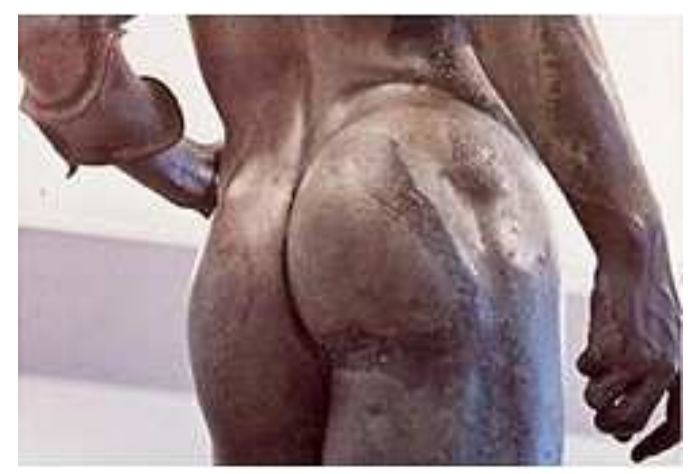

Fig. 9: Riace Warrior A

Yet the gap between art and reality is even more accentuated in the case of the Riace bronzes. Spivey (1996:40) draws attention to a feature that is anatomically impossible: namely, the continuation of the iliac crest around the back of the figure, as seen in Fig. 9 (Riace Warrior A). While modern athletes, as already remarked, often do have well-developed iliac crests and abdominal muscles, it is clear that Classical nudes, like the Doryphoros and the Riace Warriors, display features whose definition, in the words of Spivey again, "would, in fact, defy any amount of training". A few more images will suffice to show that the iliac crest and the protuberance of the lower abdominal muscles are regularly accentuated in a manner often out of keeping with the figure's general muscle development. Fig. 10 is worth studying from two angles:
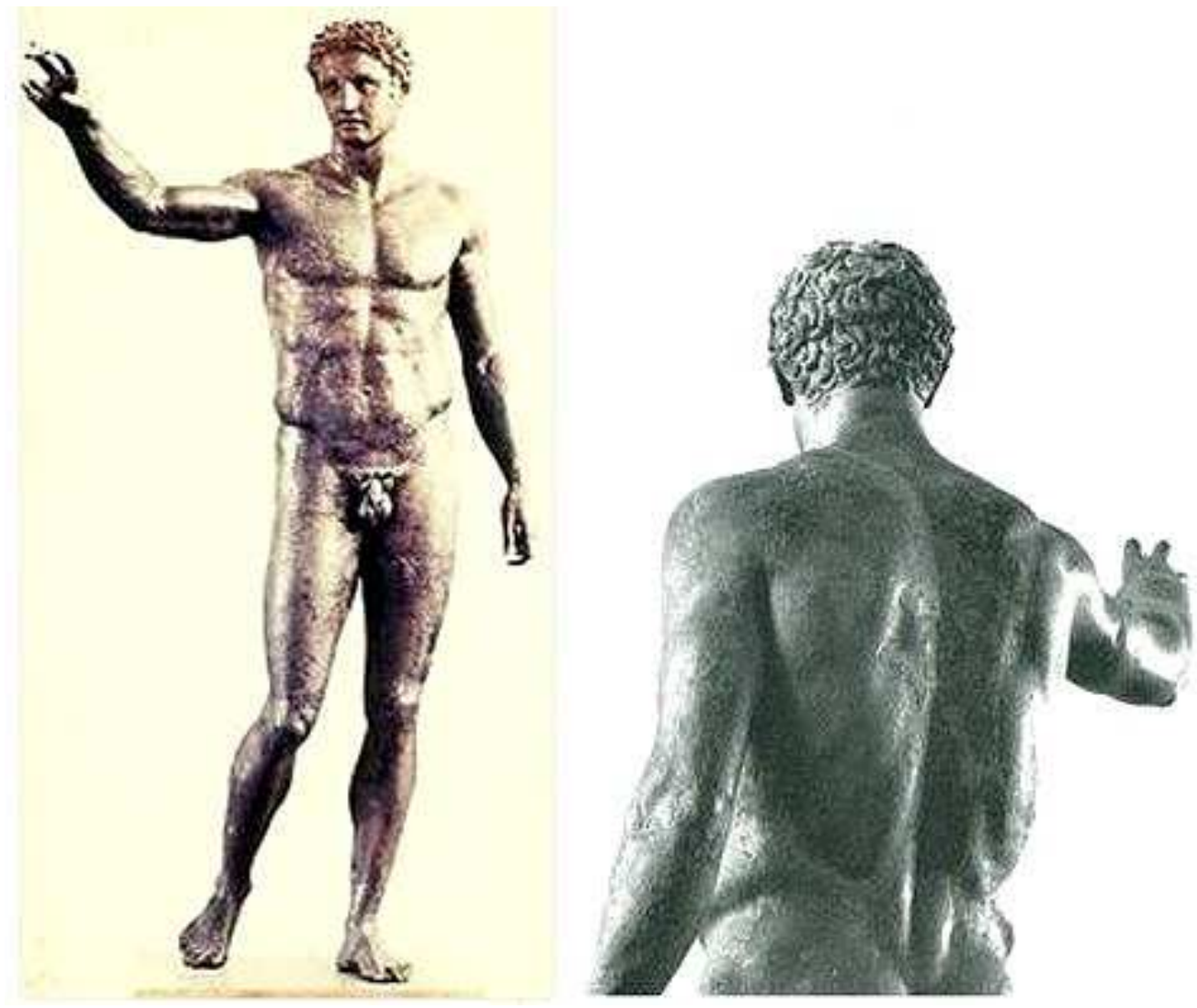

Fig. 10: Bronze from Anticythera $3^{\text {rd }}$ quarter $4^{\text {th }}$ century $B C$

In the next example (Fig. 11), note how the smooth curve of the lower abdomen is rendered independently of the pubic hair: 
Compared to modern athletes and bodybuilders, some of these ancient Greek nudes - like the Bronze from Anticythera and the Diadoumenos - look somewhat flabby around the waist; and it is interesting to note that Galen, writing towards the end of the $2^{\text {nd }}$ century $\mathrm{AD}$, made some highly disparaging remarks in his Exhortation for medicine (9-14) about athletes in his day, particularly with respect to their eating habits:

... [Athletes] are so deficient in reasoning powers that they do not even know if they have a brain. Always gorging themselves on flesh and blood they keep their brains soaked in so much filth that they are unable to think accurately and are as mindless as dumb animals [...] Athletes overexert every day at their exercises, and they force-feed themselves, frequently extending their meals until midnight $[. .$.$] In fact their lives are just$ like those of pigs, except that pigs do not overexert or force-feed themselves. ${ }^{2}$

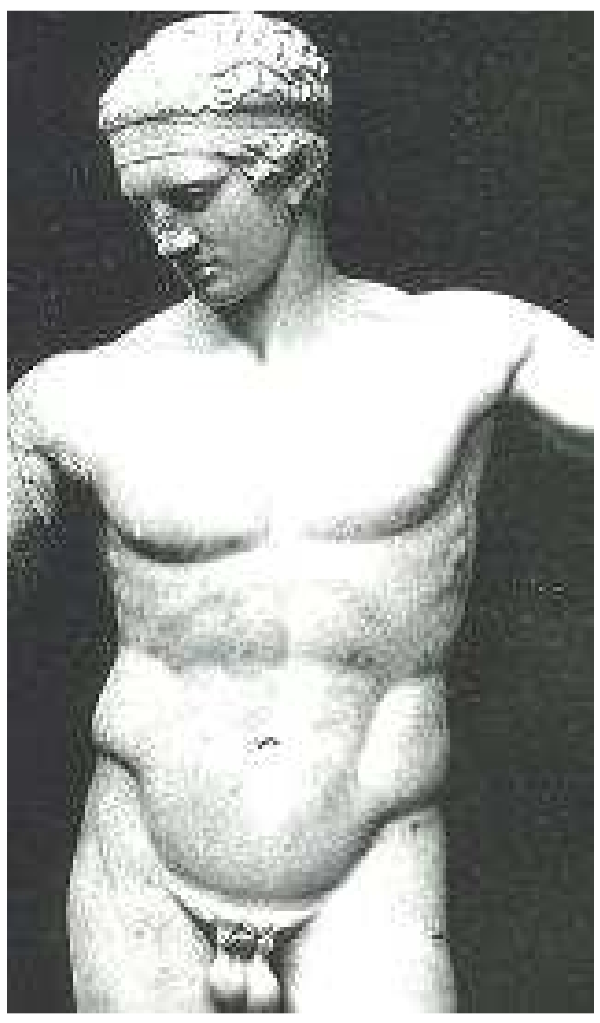

Fig. 11: Diadoumenos, c. 430 BC

Galen's intemperate criticisms were directed at professional athletes - but what of his contention that athletes overexerted themselves? Is there reason to believe that the nature and intensity of the exercise regime of the gymnasia and palaistrai could have produced the extraordinary muscular development in the region of the hips and lower abdomen, as observed in a number of statues? Did the ancient Greeks undergo a weight-training regime at all comparable with that followed by modern athletes? One can hardly point to Milo's alleged feat of carrying a heifer around the altis at Olympia as a serious precursor of modern progressive resistance exercise; and the story that he proceeded to devour the entire beast on his own would surely have negated the benefits of the exercise - and justified Galen's criticisms in a spectacular manner. There is some evidence from vase-paintings that suggests that athletes may have used halteres, or jumping-weights, for general strength training, but this is hardly comparable to the variety of equipment and intensely focused weight-training available in the modern gymnasium. Running, jumping, discus and javelin throwing, wrestling and boxing - the staple regime of the ancient Greek gymnasion and palaistra - are unlikely to have produced the exaggerated physical feature that is the focus of this discussion.

How, then, are we to account for this curious anomaly in the portrayal of the male figure by Greco-Roman sculptors? In creating the Doryphoros, a name probably not of the artist's devising (Stewart 1997:88), Polykleitos gave expression to a type of male physique, that was to inspire three generations of his pupils and influence

$2 \quad$ Miller 1979:88-89. 
sculptors of the Roman empire too (Quintilian Inst. 5.12.21 remarked that when the most renowned sculptors and painters wanted to carve or paint figures that were the most beautiful possible, they never fell into the error of taking "some fat eunuch" as a model, but rightly selected the well-known Doryphoros, a physique suitable both for war or athletics).

Polykleitos also wrote a work, entitled the Canon or Rule, in which he set out in detail the artistic principles that governed his sculpture. Unfortunately, reliance on only two brief quotations from the treatise by Plutarch (Mor. 86a, 636c) and several paraphrases by Galen makes detailed understanding of Polykleitos' system impossible. What is clear from our sources is that the proportions of his statues were based on precise numerical relationships. According to Galen, "Chrysippos holds beauty to consist in the proportions ... of the parts, that is to say, of finger to finger and of all the fingers to the palm and wrist, and of these to the forearm, and of the forearm to the upper arm, and of all the parts to each other, as set forth in the Canon of Polykleitos" (de Plac. Hipp. et Plat., 5).

Attempts to ascertain the precise ratios of Polykleitos' formula have not been successful - partly because we cannot be sure of exactly how faithful Roman copies are to the original - and any attempt to solve the problem is made all the more daunting by Polykleitos' own statement to the effect that perfection is the result of numerous calculations, carried to within a hair's breadth. However, it seems inconceivable that the proportions of the iliac crest and the abdominal muscles to that of the rest of the torso were not also somehow determined by Polykleitos' system of $\sigma v \mu \mu \varepsilon \tau \rho^{\prime} \alpha$ (symmetria) or "commensurability".

It is likely that the heavily muscled lower torso of this statue contributed in no small measure to the use of the word quadrata ("squarish" or "blocklike") in describing this work. According to Pliny the Elder, "it was purely [Polykleitos'] own invention to make his statues throw their weight on one leg" (NH 34.56) and he mentions Varro's statement that his figures are "squarish (quadrata) and almost all based on a single model"; and later Pliny refers to Lysippos' alteration of the "square" builds of the body (quadratas ... staturas) used by the older sculptors (NH 34.65).

Not surprisingly, the Greek equivalent $\tau \varepsilon \tau \rho \alpha ́ \gamma \omega v o \varsigma$ (tetragōnos: "having four angles") was applied to Archaic sculpture ${ }^{3}$ and to architectural forms. ${ }^{4}$ The analogy between sculpture and architecture is instructive in the case of Polykleitan sculpture and has given rise to some interesting observations. Gardner (1905:22), for example, points out that it was quite natural that the Greeks, with their strong tendency towards introducing simple mathematical relations, should have transferred to sculpture the remarkable care and minuteness with which they regulated the proportions of columns and other parts of their temples. Clark (1956:19), in contrasting the overall frontality of the ancient Greek nude with the radiating axes of its Renaissance

3 Themistius Orationes 15.316a: "Before the time of Daedalus not just the workmanship of herms was "squarish", but also the style of other statues as well".

4 Diodorus Siculus 17.115.2: "they erected the entire structure on quadrilateral plan"; Diodorus Siculus 18.26.5: "a golden cornice which was square in format"; Athenaeus 196B: "a square epistyle". 
counterpart, compared the antique nude to a Greek temple, with "the flat frame of the chest being carried on the columns of the legs".

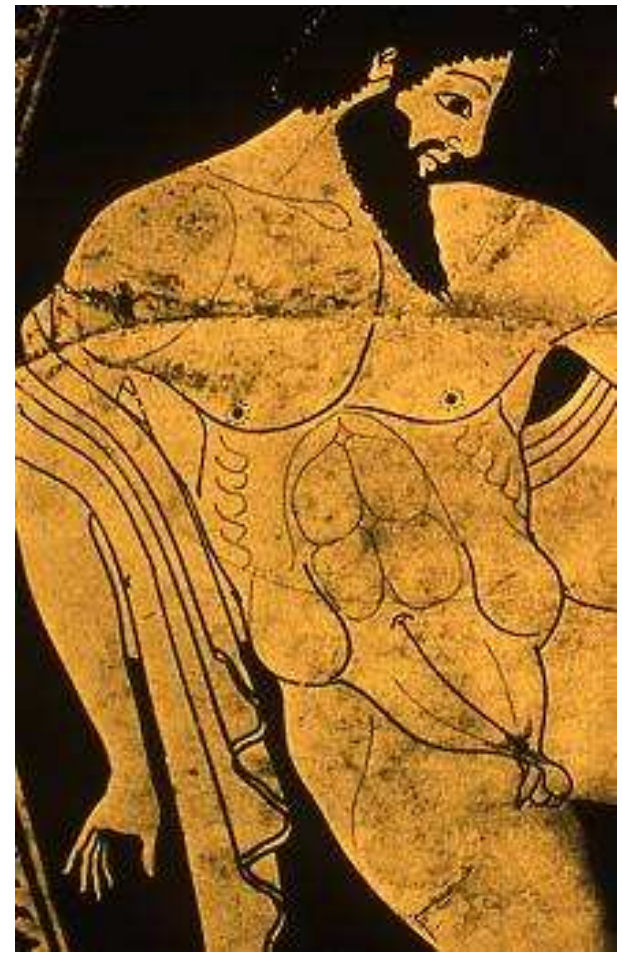

Fig. 12: Detail from Euthymides'

Three revellers c. $510 \mathrm{BC}$

In the case of the Polykleitan torso, it may be said that the exaggerated iliac crests do, in a way, balance the mass of the upper torso (specifically the pectoral muscles) and impart a sense of sturdiness and solidity rather like an architrave supporting a pediment. To pursue the architectural analogy further, the impression of carefully positioned and proportioned 'building blocks' is clearly evident in the simplified and rather schematic configuration of the male torso in vase paintings, as seen in Fig. 12.

However, while the architectural analogy might be useful in understanding the relationship between the lower and upper parts of the Polykleitan torso, it would appear that the prominent contour of the iliac crest and its continuation in the contour of the lower abdomen also served several important artistic purposes: first, it separated - in an emphatic manner - the torso from the legs. I use the word "separated" deliberately, because the tendency to isolate the legs from the upper torso is a salient feature of the representation of the male body in both sculpture and vase-painting - as already observed. Pollitt (1972:5) has aptly remarked that one of the most essential aesthetic principles underlying Greek artistic expression is the analysis of forms into their component parts; the Greek artist, he maintains, "chose to stand aside from nature, to analyse what its constituent elements were, and then to reshape it according to his conception of what it should be". This tendency to see the human body as an amalgam of discrete parts is most obvious in the case of early Archaic kouroi, but it is also evident in Polykleitos' apparent preoccupation with a numerically based relationship between the various parts of the body and in the readiness of artists to exaggerate the dimensions of a particular part for visual effect. For example, in discussing Lyssipos' Apoxyomenos, Pliny NH 34.65 remarks that, by making the head smaller and the body more slender, the sculptor imparted a sense of greater height and exchanged "the squarely built figure of the older artists for a new and untried system". 


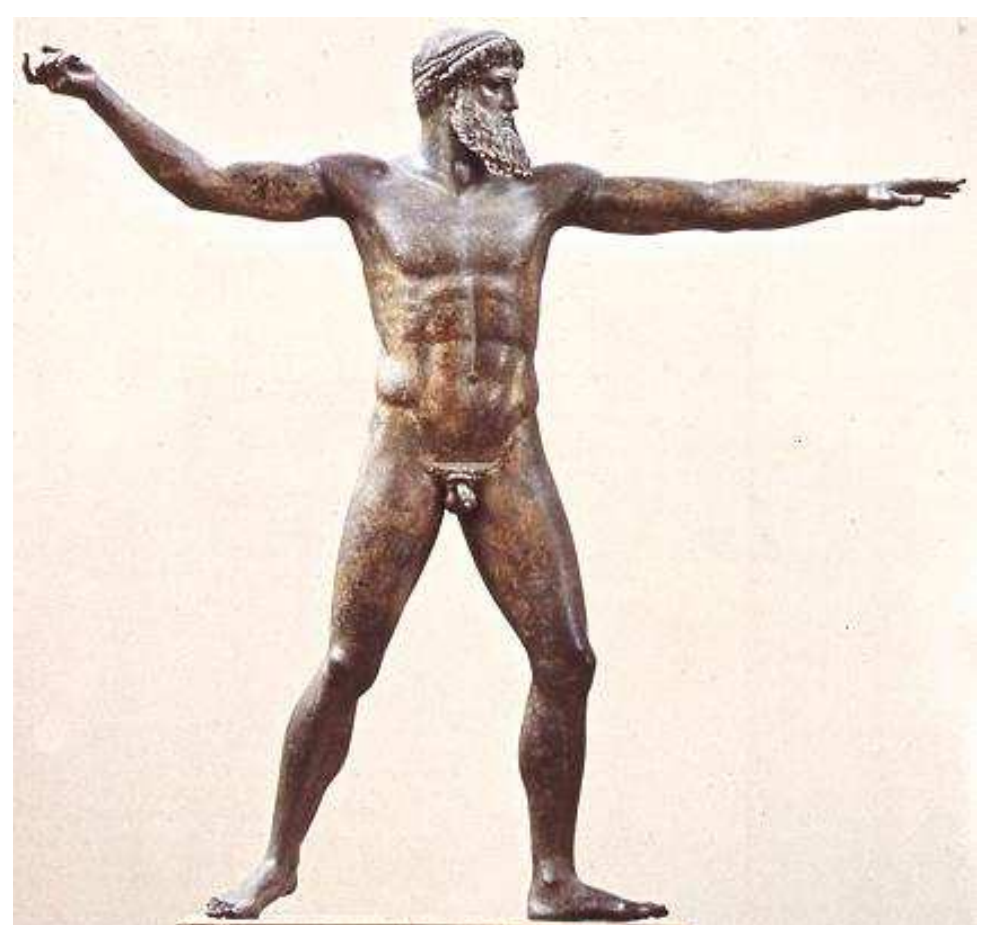

Fig. 13: Artemision "Zeus" c. 460 BC

It is also interesting to note that the famous early Classical bronze figure of Zeus (or Poseidon) has arms whose length is actually out of proportion with the rest of its body - a clear example of manipulating measurement and proportion for artistic effect (Fig. 13).

Perhaps the most interesting - albeit anecdotal - evidence of the Greek preoccupation with the component parts of a form is the story about the painter Zeuxis, who was approached to paint a figure of Helen for the people of Croton. He accepted the commission on condition that he had the opportunity of studying the most beautiful virgins of the city, whose outstanding attributes he combined to produce his idealized version of Helen. ${ }^{5}$

Such stylistic distortions and exaggerations point to a factor of overriding importance in the portrayal of the male figure in Greek sculpture: the role of idealism. Not only do the highly schematic forms of early Archaic kouroi express an idealized concept of the human form, but it is clear that the apparent progression towards naturalism in Greek sculpture, as sketched at the beginning of this discussion, is, in part, an illusion: even though one may point to the anatomical accuracy of many details in the Doryphoros, the fundamental artificiality of Polykleitos' numerically based system is inconsistent with the notion of absolute realism. More to the point, the divide between the real and the ideal is made abundantly clear when one attempts to harmonize, for example, the uniformly serene and beautiful male figures of the Parthenon frieze with the unpalatable archaeological evidence. According to Grmek (1989:110), “[t]he inhabitants of Greece in Mycenaean, archaic and classical periods were thickset and sturdy, with relatively short lower limbs. The image of their general 
appearance that one obtains from osteoarchaeological evidence does not coincide with the idealized representation of the human body in Greek sculpture".

The second effect of the exaggerated iliac crest was that it accentuated the pronounced tilt of the pelvis - the basis of the element of contrapposto, or dynamic equilibrium, that revolutionized the representation of the human form in the early Classical period and that was exploited to an extreme by the sculptor of Riace Warrior B, for example (see above Fig. 7).

Finally, there is a third effect of the pronounced iliac crest that I think is worthy of consideration: not only did it differentiate clearly between the legs and the torso and accentuate the contrapposto pose, but its pronounced overhang — with its aesthetically pleasing contour — also tended to emphasise the length and prominence of the thighs in relation to the upper body, a feature that would appear to be accentuated in Fig. 14. I draw attention to this, because the evidence from both literature and art makes it clear that the male's thighs were an important focus of homoerotic interest - an interest that found ample to fixate upon in the contexts of athletic competition and especially of the gymnasion, which became such an important cultural institution from the $6^{\text {th }}$ century onwards. That the thighs were a focus of homoerotic desire is also evident, naturally, in the practice of intercrural intercourse between erastes and eromenos.

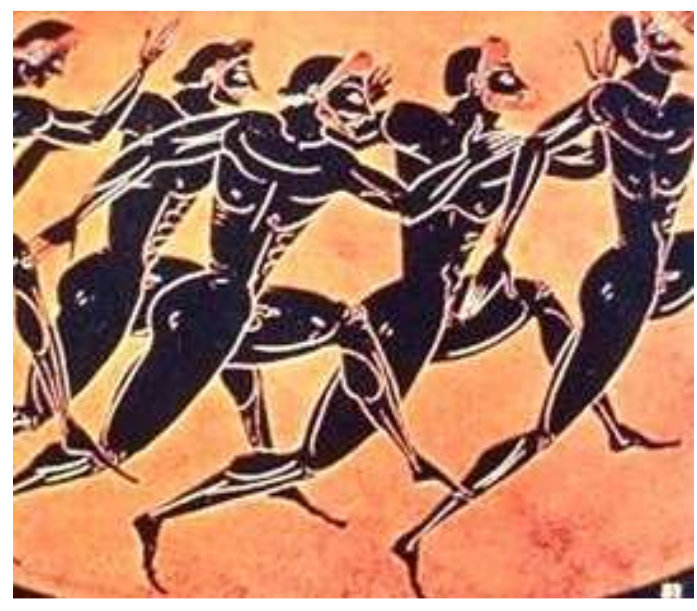

Fig. 15: Panathenaic vase painting c. 525 BC

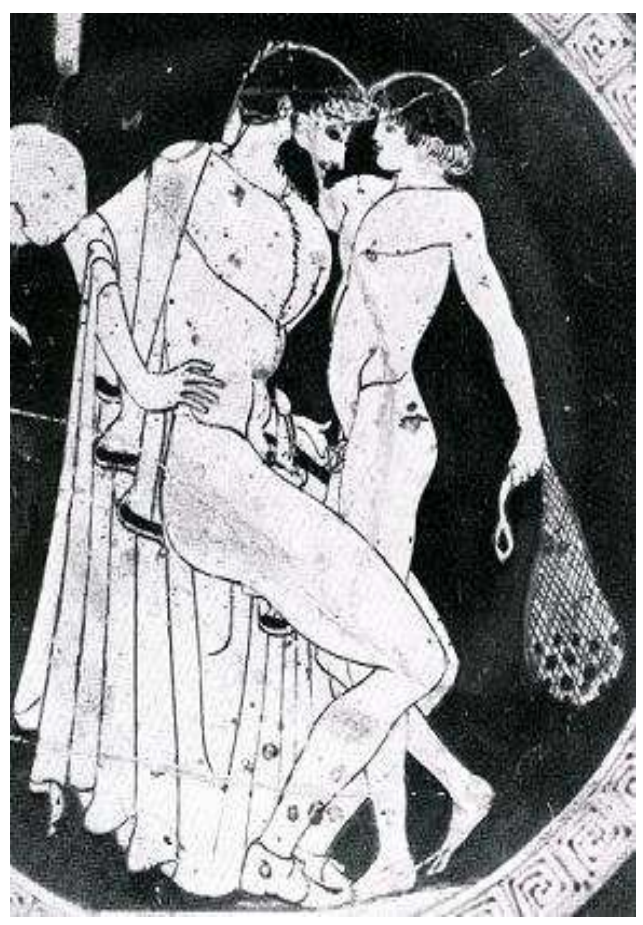

Fig. 14: Attic red-figure plate
530-430 BC

While it seems generally agreed that physical homoeroticism is absent from, or at best implied in, Homer, the Odyssey provides at least one example of thighs as a focus of admiring looks. When Odysseus prepares to box against the bully Iros, he tucks up his rags and bares "his great and shapely thighs" (Od. 18.66-69). The importance attached to large, muscular, and even elongated thighs is often evident in vase paintings, as seen in Fig. 15, a vase illustration of sprinters. 


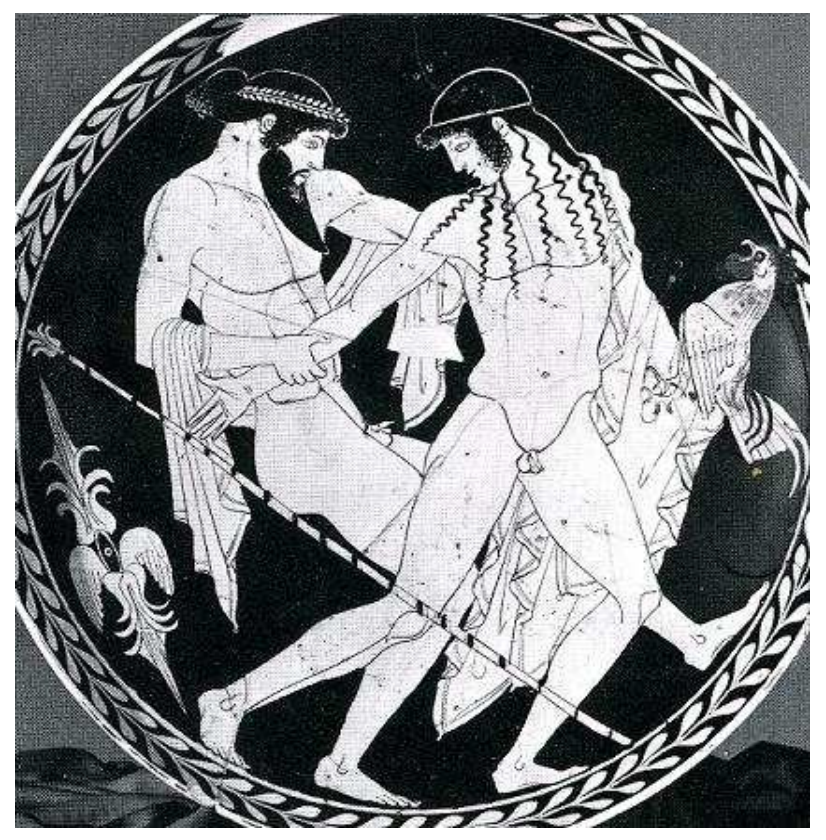

Fig. 16: Red-figure plate c. $450 \mathrm{BC}$

Of particular relevance to the present discussion are two fragments (228-229) from one of Aeschylus' plays, in which the relationship between Achilles and Patroklos is characterized as overtly homoerotic: in the first, Achilles reproaches the dead Patroklos for abandoning him: “Ah, Patroklos ... you felt no compunction for my pure reverence of your thighs; o what an ill return you have made for so many kisses"; and, in the second, there is mention of the "godfearing converse with your thighs".

A similar emphasis on the homoerotic stimulus provided by this part of the male anatomy is preserved in a fragment of Sophokles (320), in which we are told that Ganymede's thighs "set Zeus aflame" - a moment quite well captured in this scene from an Attic cup, shown in Fig. 16 above. Probably better known is the portrayal of Ganymede in Fig. 17.

Note how, in both depictions, the youth sports a precociously well-developed iliac crest that accentuates the seductive sweep of his thigh. Perhaps the hoop in this instance was intended to serve as a framing device to emphasize this special focus of the male gaze!

Is it possible that herein lies the explanation of why Greek artists gave such emphasis to this "unnatural" characteristic in their portrayal of the male physique?

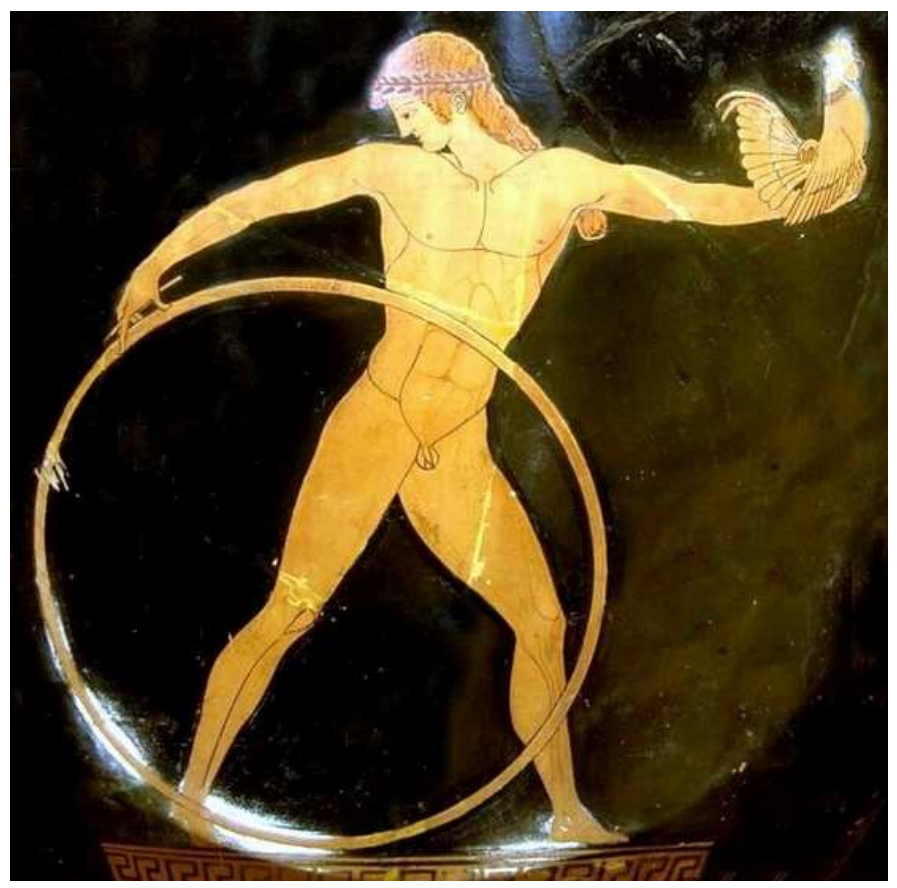

Fig. 17: Red-figure painting on an Attic bell-krater, c. 490 BC 


\section{BIBILIOGRAPHY}

Clark, K 1956. The Nude: a study of ideal art. London: Murray.

Gardner, P 1905. A grammar of Greek art. New York: Macmillan.

Grmek, M 1989. Diseases in the ancient Greek world. Baltimore: Johns Hopkins University Press.

Miller S G 1979. Arete: ancient writers, papyri, and inscriptions on the history and ideals of Greek athletics and games. Chicago: Ares Publishers, Inc.

Pollitt, J J 1972. Art and experience in Classical Greece. Cambridge: Cambridge University Press.

Spivey, N 1996. Understanding Greek sculpture: ancient meanings and modern readings. London: Thames and Hudson.

Stewart, A 1997. Art and desire and the body in ancient Greece. Cambridge: Cambridge University Press. 